\title{
Campanhas de Educação de Jovens e Adultos - EJA: Aspectos Históricos e Avanços
}

\author{
Edjonas Silvana Lopes ${ }^{1}$; Francimária Sousa Santos Silvana ${ }^{2}$ Eronilda Gomes Damasceno ${ }^{3}$
}

\begin{abstract}
Resumo: Este trabalho pretende refletir sobre a Educação Brasileira voltada especialmente para os jovens e adultos da nação, desde os antepassados dos índios, passando pelo Brasil colônia, pela república até chegar à contribuição de Paulo Freire. A questão do analfabetismo já foi considerada "a vergonha nacional" por isso cabe conhecer e distinguir cada momento histórico e político, como palco das grandes campanhas de alfabetização em massa, dentre elas as três principais foram: a primeira de 1947, Campanha de Educação de Adolescente e Adultos -CEAA; a segunda de 1952, Campanha Nacional de Educação Rural -CNER; e na terceira posição, ainda na década de 50, a Campanha Nacional de Erradicação do Analfabetismo -CNEA. Além dessas campanhas, o MOBRAL também foi um projeto de Alfabetização de efeito gigantesco e que merece destaque nesse artigo. Cada campanha ou movimento social tinha objetivos em comum, a educação, para aqueles que não tiveram acesso a ela na idade adequada. Finalizando pela proposta metodológica de Laubach, contratado para orientar professores para atuar no Brasil em diversas campanhas.
\end{abstract}

Palavras-chave: Campanha. Educação. Analfabetismo. Jovens e Adultos.

\section{Youth and Adult Education Campaigns: Historical Aspects and Advances}

\begin{abstract}
This work intends to reflect on the Brazilian Education focused especially on the youth and adults of the nation, from the ancestors of the Indians, passing through Brazil colony, by the republic until arriving at the contribution of Paulo Freire. The issue of illiteracy has already been considered "national shame", so it is important to know and distinguish each historical and political moment, as the stage of the great mass literacy campaigns, among them the three main ones were: the first of 1947, Adolescents and Adults - CEAA; The second of 1952, National Campaign for Rural Education -CNER; And in the third position, still in the 50's, the National Campaign to Eradicate Illiteracy -CNEA. In addition to these campaigns, MOBRAL was also a literacy project with a gigantic effect that deserves to be highlighted in this article. Each campaign or social movement had common goals, education, for those who did not have access to it at the appropriate age. Finalizing the methodological proposal of Laubach, contracted to guide teachers to work in Brazil in several campaigns.
\end{abstract}

Keywords: Campaign. Education. Illiteracy. Youth and Adults.

\footnotetext{
${ }^{1}$ Especialista em Biologia Geral, Mestrando em Ciências da Educação, graduado em Ciências Biológicas. Professor na rede municipal de ensino na cidade de Araripina-PE. Email: edjonassilvana@gmail.com

${ }^{2}$ Especialista em Geografia Geral, Mestranda em Ciências da Educação, graduada em Geografia. Professora na rede municipal de ensino na cidade de Araripina. Email: francisousa87@gmail.com

${ }^{3}$ Especialista em Psicopedagogia e Gestão e Avaliação Escolar. Mestranda em Ciências da Educação. Analista Educacional em Pedagogia.
} 
Id on Line Revista Multidisciplinar e de Psicologia

Id on Line Multidisciplinary and Psycology Journal

\section{Introdução}

A História da Educação de Jovens e Adultos é marcada por muitos movimentos e práticas formais e informais. Os alunos foram alfabetizados em diferentes espaços, em comunidades, no comércio, no convívio familiar, em igrejas, em espaços culturais e de lazer, no trabalho, como também através dos meios de comunicação pelas vias do rádio.

Sabe-se que os jesuítas foram os primeiros professores no Brasil, onde seu objetivo maior foi à catequização do povo para que eles fossem multiplicadores e ampliassem assim o domínio da igreja. Nesse sentido, a Constituição de 1934 estabeleceu a criação de um Plano Nacional de Educação, no qual foi mencionada pela primeira vez a educação de adultos, sendo dever do Estado à mantença, além de ser gratuito e obrigatório, inclusive para adultos.

A partir da década de 40, finalmente a educação de adultos veio se firmando como um problema de política nacional, resultante na criação e ampliação de algumas iniciativas para a educação de jovens e adultos: a criação do Instituto Nacional de Estudos e Pesquisas (INEP), o lançamento da primeira grande campanha de educação de massa, a Campanha de Educação de Adolescentes e Adultos (CEAA). Lourenço Filho, o mentor da campanha tinha dividido em sociais e individuais os objetivos dessa missão lhe confiada.

Em seguida surgiu a segunda e depois a terceira campanha em todo o país, além dos diversos movimentos informais e formais, na ideia de sanar a vergonha nacional, diante da UNESCO e outros países.

\section{Antepassados dos Povos Indígenas}

Antes dos portugueses chegarem ao Brasil, o país já era habitado pelos índios, povo esse que tinham e tem uma cultura diferenciada, costumes que visam a preservação do meio ambiente, em todas as situações. Porém, muito antes dos índios, existiu outro povo, outras pessoas aqui no Brasil, conhecido como os antepassados dos índios, mas o conhecimento que se tem sobre eles é limitado, apenas informações que vieram de buscas e pesquisas feitas pelos arqueólogos, que durante anos vivem a escavar a terra em busca de respostas sobre os povos antigos. Nas palavras de BOULOS JÚNIOR (2006, p.68), 
É pouco ainda o que se sabe sobre a vida dos "descobridores do Brasil". Não as sabe, por exemplo, que língua falavam. Sabe-se, no entanto, que muitos deles viviam em cavernas, faziam pinturas nas paredes de suas moradias e lascavam pedras para fazer machados. $\mathrm{O}$ fogo tinha grande importância em suas vidas. Costumavam fazer fogueiras para aquecer seus corpos, cozinhar e afugentar animais perigosos, como o tigre-dedente-de sabre.

Mediante citação acima pouco se sabe sobre os antepassados dos que antecederam os índios, mas nota-se que eram inteligentes o suficiente para usar recursos disponíveis da natureza para garantir a auto sobrevivência, bem como fazer ferramentas de pedras ou fazer pinturas nas rochas, os quais ainda hoje são motivos de estudos.

Com a descoberta do fogo, a grande descoberta da época, tudo mudou na maneira de viver desse povo, aprenderam a usar o fogo para cozinhar seus alimentos, como também para se proteger de animais selvagens. Quanto à educação, imagina-se que ela acontecia de forma condicionada e por repetições, observações, enquanto o adulto fazia uma atividade de caça ou mesmo um ritual de suas crenças, a criança ficava a observar para repetir. Jamais poderiam pensar ou desejar uma educação escolar, já que a única necessidade era mesmo a sobrevivência dentro da floresta nativa brasileira.

\section{Os Jesuítas}

Os Jesuítas foram os primeiros alfabetizadores a pisar no Brasil, estes estavam a serviço do coroa de Portugal, o rei havia lhes enviado para trabalhar em prol de objetivos sociais e econômicos reais, bem como difundir a crença do catolicismo.

Nesse momento histórico do Brasil, a educação era uma prioridade dada às crianças, mediante alegação que os adultos já eram cheios de vícios e "paixões barbaras" (SOARES e GALVÃO, 2004). As crianças educadas deveriam ser a futura geração católica, seguir os costumes e tradições adquiridos, sem contar que poderiam ser usadas como multiplicadores em seu convívio social. Mesmo assim, muitos índios adultos foram alfabetizados. Não há registro de educação voltada para as mulheres, todas estavam fora da classe estudantil.

Os jesuítas ensinavam regras, normas, bons modos de comportamentos, programa, denominado de "Ratio Studiorium” (SOEK, HARACEMIV, STOLTZ, 2009, p.7), o qual era 
Id on Line Revista Multidisciplinar e de Psicologia

Id on Line Multidisciplinary and Psycology Journal

transmitido basicamente pela oralidade, tendo em vista que a população ainda não tinha acesso a escola e nem a escrita.

Tempo depois surgiram as escolas, porém eram destinadas aos colonizadores e aos seus filhos. Cabe ressaltar que a escrita dessa época era pautada numa cultura machista, racista e cristã e assim mulheres, negros e índios nãos tinham acesso à escola.

Em 1924, o Brasil elaborou a sua primeira Constituição Federal, a qual veio fazendo menção de uma educação para todos os cidadãos, mas é de conhecimento popular que durante anos essa educação foi destinada somente para poucas pessoas, os ricos e nobres da sociedade, excluindo rigorosamente os pobres e exatamente por essa condição eram menos favorecido ou lembrados. Conforme o "censo de 1920 havia um índice de $72 \%$ da população acima de cinco anos de idade fora da escola, que nunca havia ido à escola”. (ibid,p.8). Chega a ser assustador pensar nesse índice tão elevado de analfabetos, mas foi fato real na colônia portuguesa.

No censo de 1872 e 1890 as informações coletadas resultaram que a maioria da população acima de 5 anos não estudavam e a condição de analfabetos atingia diferentes faixas etárias. Quando ocorreu o terceiro censo, em 1900 iniciou-se pela primeira vez a contagem por porcentagem dos dados. O resultado desse censo foi assustador, calculou-se que $65,3 \%$ de pessoas com mais de 15 anos eram analfabetos. (LOURENÇO FILHO, apud, CARVALHO, 2010, p.16).

\begin{abstract}
Com o fim da Primeira Guerra Mundial, a década de 1920 foi marcada por grande interesse pela educação elementar, trazendo à tona a necessidade de combater o analfabetismo entre os adultos. A realização do Censo de 1920 demonstrou praticamente o mesmo percentual de analfabetos maiores de 15 anos: 64,9\% em 1920 contra $65,3 \%$ em 1900. Por outro lado o número absoluto de analfabetos com idade acima de 15 anos havia praticamente dobrado.
\end{abstract}

O Período de transição da Monarquia para República foi alvo de grandes transformações na esfera econômica, política e social. Além do fim da escravidão, o país passou a receber imigrantes europeus, que vieram para se instalar na nova república. Surgir nesse contexto um crescimento industrial considerável, no qual os grupos políticos e econômicos passaram a disputar o poder e posição social perante o governo.

Apesar da circulação de ideais liberais republicanos entre a população, quanto à industrialização e o progresso nacional, notou-se que não surtiu reações o suficiente para gerar transformações sociais significativas. 
Id on Line Revista Multidisciplinar e de Psicologia

Id on Line Multidisciplinary and Psycology Journal

O número de analfabeto ainda era exagerado, como isso o Estado promoveu um reforma educacional em 1928, substituindo os antigos cursos noturnos para adultos por outros chamados de "cursos populares noturnos". A grade curricular desses novos cursos estava pautada basicamente em noções de higiene e elementos da cultura geral.

\section{O Plano Nacional de Educação}

Finalizando a década de 1940 a educação de adultos veio se firmando como um problema de política nacional, resultado de condições e ações governamentais anteriores. Com a criação do Plano Nacional de Educação de responsabilidade da União, finalmente a educação de jovens e adultos foi enxergada como uma necessidade urgente, tendo assim um tratamento particular e com objetivos definidos.

Segundo HADDAD e PIERRO (2000) O INEP - Instituto Nacional de Educação Pedagógica criou em 1942 a Fundação Nacional de Ensino Primário e este deveria utilizar seus recursos para planejar e exercitar em programa progressivo e contínuo de ampliação de educação da educação primária que incluísse o Ensino Supletivo para adolescentes e adultos. O novo plano estabeleceu que $25 \%$ de seus recursos estavam destinados ao Ensino Supletivo, oferecendo inúmeras vagas e qualidade ao ensino aprendizagem da EJA. (p.111)

Logo após a Segunda Guerra Mundial, dezenas de países uniram-se no mês de novembro de 1945 para criar uma organização, um órgão que pudesse posicionar-se perante os problemas dos países participantes. Esse órgão é a UNESCO -Organização das Nações Unidas para a Educação, a Ciências e a Cultura.

A UNESCO havia denunciado os problemas do Brasil, principalmente o alto índice de analfabetismo. Além de alertar o país, o órgão citado relembrava o dever de manter o desempenho na educação, especialmente aos adultos que precisavam do trabalho, já era a mão de obra utilizada para fazer progredir a nação. 
Id on Line Revista Multidisciplinar e de Psicologia

Id on Line Multidisciplinary and Psycology Journal

\section{A Era Vargas}

A era Vargas é denominada um período de 15 anos de dominação e poder exercido pelo ditador Getúlio Vargas, de 1930 a 1945. Período esse que deixou inúmeras marcas na história do Brasil, em virtude das muitas mudanças feitas, tanto no setor social como econômico. O governo provisório de Vargas tratou logo de início de reorganizar a vida política do país, centralizando todo o poder em suas mãos ou nas mãos de militares de sua confiança, que ocupava os principais cargos do governo.

A Constituição de 1934, tendo como chefe o ditador Getúlio Vagas trouxe vários direitos a cidadão, tais como: “Consolidação das Leis do Trabalho, o Código Penal. O governo atual foi responsável pela emissão da Carteira de Trabalho, da Justiça do Trabalho, do salário mínimo, e pelo descanso semanal remunerado". (SOHISTÓRIA). Na área da educação veio reafirmando a obrigatoriedade e gratuidade do ensino primário, inclusive para os adultos, que estavam afastados da escola, independente da razão, da classe social, crença religiosa ou sexo.

\section{O Fim da Era Vargas}

No ano de 1947, com o fim do governo de Getúlio Vargas, o país estava eufórico, sonhando com uma redemocratização, com a divisão de poderes e direitos garantidos. Pensando, sobretudo em aumentar a base eleitoral brasileira, em 1947, Lourenço Filho, lançou a Campanha de Educação de Adultos, a qual se fundamentava em estudos de psicologia experimental realizadas nos Estados Unidos na década de 1920 e 1930. (SOEK, HARACEMIV, STOLTZ, 2009, p.8).

Enquanto no período da colonização não havia nenhuma preocupação em institucionalizar a escola, no período imperial essa preocupação é forte no Brasil, e em meio à definições de tempo, espaços, saberes e materiais escolares - para a instrução primária e secundária para crianças - formulada, especialmente, a instrução para jovens e adultos da camadas denominadas "camadas inferiores da sociedade!. Um dos objetivos dessa instrução era a civilização desse grupo, principalmente na área urbana, e a correção da dicção, considerada "erronia", através das aulas de língua materna.

Na fala de SOARES e GALVAÃO, (2004) a língua materna deveria ser ensinada prioritariamente, pensando na civilização das pessoas que antes não haviam frequentado uma 
Id on Line Revista Multidisciplinar e de Psicologia

Id on Line Multidisciplinary and Psycology Journal

escola. Entretanto, nessa época as turmas eram divididas por gêneros, classe dos homens e classe das mulheres. Além da língua materna as mulheres estavam destinadas a servir a família, aprendiam a costurar, bordar, ser uma boa esposa, boa mãe, ter noções de higiene, cálculos para ajudar nas contas doméstica e demais deveres na família,

Na verdade as aulas tinham um caráter filantrópico e missionário. Filantrópico porque o professor trabalhava praticamente sem pagamento, de forma voluntária ou sob pressão política. Missionária por está enraizado nas ideias religiosos dos jesuítas.

Diversas atividades e experiências informais de educação de adultos foram percebidas. Os escravos negros com atividade nos centros urbanos e os escravos da igreja tiveram contato com textos orais, por brancos, que promoviam a memorização e o reconhecimento posterior do texto memorizado, promovendo assim a alfabetização e o aprendizado da leitura e escrita tão necessárias para esse grupo conquistar seus direitos civis. (ibid.; 2004).

\section{Primeira Campanha de Educação de Adolescente e Adulto- CEAA}

As esperanças estavam sendo renovadas, depois de passar pelo doloroso período da ditadura militar. Durante a campanha eleitoral para Presidente da República o candidato Eurico Gaspar Dutra disse que caso fosse eleito acabaria com o analfabetismo no Brasil, promovendo campanhas de Educação de massa intensiva e duradoura.

Dutra, como presidente do país, começou a promover as primeiras ações para cumprir a promessa de campanha. De início ele promoveu o então diretor do Departamento Nacional de Educação e educador a missão de planejar e criar os meios de realização de uma grande campanha de alfabetização, a qual fosse ampla, chegasse a todas as capitais e cidades do interior.

Os objetivos dessa grandiosa Campanha não era somente alfabetizar a população, os responsáveis pelas ideologias, com exemplo, o atual ministro de Educação Clemente Mariani, declarou publicamente que os objetivos mais ambiciosos eram: "a educação do povo nos melhores moldes democráticos" e não a mera alfabetização. Acrescentou ainda que criaria "centros de comunidade" ambiente propício para adolescentes e adultos terem acesso à rádio, cinema, livros e jornais. (BRASIL, CEAA, 1949a. apud CARVALHO, 2010, p.19). 
Id on Line Revista Multidisciplinar e de Psicologia

Id on Line Multidisciplinary and Psycology Journal

Lourenco Filho dividia os objetivos da Campanha em sociais e individuais. Dentre os benefícios individuais, desejavam que a educação de base viesse a promover o desenvolvimento da personalidade, a facilitar a expressão pessoal, além de permitir "o gozo dos bens da civilização e da cultura". Quanto aos objetivos sociais à educação a campanha deveria ser capaz de "aumentar a harmonia e a integração na vida coletiva, com ordem, justiça e melhor produção (BRASIL, CEAA, $1948^{\mathrm{a}}$ apud CARVALHO, 2009, p.20)

Os analfabetos eram a vergonha do país, conforme mencionado anteriormente, e por essa condição suas características eram os piores possíveis para um trabalhador: "ineficiência de trabalho, incapacidade política e jurídica, incompetência para cuidar da própria saúde e até mesmo dos filhos". (ibid., p.20) Por essas razoes a educação de base era a única saída, o inicio para solução dos problemas da população marginalizada e excluída.

\section{Segunda Campanha Nacional de Educação Rural (CNER)}

Um ano depois da primeira campanha, Lourenço Filho percebeu que os resultados eram satisfatórios nas cidades, porém ficava a desejar no interior, especialmente nas comunidades mais distantes dos centros urbanos. No ano de 1948 ele dividiu a primeira campanha em duas, nascendo então a Campanha Nacional de Educação Rural (CNER), a qual estava sendo inspirada em experiências mexicanas, conhecidas como "missões rurais".

Carvalho (2010) destaca que essa segunda campanha tinha parceria e ações conjuntas entre o Ministério de Educação e Saúde e o Ministério da Agricultura. Se o objetivo era educação de qualidade vinculada à agricultura, obviamente o segundo ministério não podia ficar fora de novo projeto do governo.

Uma das metas da nova campanha não era somente oferecer alfabetização as pessoas da roça, aos excluídos, mas sobretudo, transformar sua realidade socioeconômica, proporcionando condições de saúde, trabalho e produção, tendo em vista, que se a população é instruída, bem informada, ela pouco adoece. $\mathrm{O}$ trabalho e produção estão ligados diretamente ao fator de sobrevivência das pessoas que estavam precisando ser alfabetizadas.

A CNER era e foi uma campanha maior, com objetivos amplos e ambiciosos. A começar pelos recursos destinados a ela que eram mais, em maior quantidade e qualidade, 
Id on Line Revista Multidisciplinar e de Psicologia

Id on Line Multidisciplinary and Psycology Journal

mediante a necessidade de deixar o professor ou a professora morando na comunidade que deveria trabalhar. Além do docente que deveria morar na comunidade deveria ter também um veterinário à disposição das pessoas. Muitas ações deveriam ser desenvolvidas com as pessoas em cada localidade, "além da alfabetização, a educação para o trabalho, a cidadania, o lazer, a saúde e o desenvolvimento comunitário", assim relata Carvalho, (2010, p.23).

Foi através dos escritos da referida campanha que mencionaram pela primeira vez a necessidade do país em fazer uma reforma agrária, objetivando melhores condições de vida as comunidades rurais. Logo na fase inicial a CNER (Brasil, CNER, 1959, p.17) expõem o seguinte:

Para romper este círculo vicioso da pobreza, o poder de público tem diante de si o encargo de empreender uma ação profunda e total sobre as comunidades rurais, unindo a educação fundamental às indispensáveis reformas da estrutura agrária.

Lourenço Filho desde o início foi a favor de oferecer a população mais qualidade na alfabetização, saber ler e escrever, além dos direitos cidadãos garantidos, almejava ainda preservar também a estabilidade política e social da época.

Como essa campanha dispunha de maiores investimentos, os recursos didáticos também eram maiores, além do docente e de uma enfermeira, a população tinha acesso a filmes educativos, palestras, panfletos, cartazes e livros específicos.

\section{Terceira Campanha Nacional de Erradicação do Alfabetismo (CNEA)}

Juscelino Kubitscheck eleito Presidente da República em outubro de 1955 assumiu o governo do país com as duas campanhas ainda em vigor, tendo Lourenço Filho como idealizador das mesmas. O novo presidente tinha planos ousados, a começar pela política desenvolvimentista, ou seja, fazer o Brasil crescer e se desenvolver "cinquenta anos em cinco".

O atual presidente do Instituto Nacional de Estudos Pedagógicos (Inep) Anísio Teixeira realizou pesquisas referentes às questões educacionais do país, onde os resultados não foram tão satisfatórios ou eram de eficácia duvidosa.

O Inep propôs partir para outros caminhos, os quais deveriam ser promissores. Com isso, dá-se início o novo projeto, a Campanha Nacional de Erradicação do Analfabetismo 
Id on Line Revista Multidisciplinar e de Psicologia

Id on Line Multidisciplinary and Psycology Journal

(CNEA). Esta devia começar como um projeto experimental, partindo de uma pequena amostra, de um município menor para só depois partir para outro lugar maior, até atingir todo o país.

A proposta era melhorar o ensino primário regular e ao mesmo tempo contribuir para a educação de Jovens e Adultos, complementando o que as campanhas anteriores não conseguiram fazer por completo.

Recorrendo a Carvalho (2010, p.27) sobre os objetivos dessa campanha, ela diz o seguinte:

\begin{abstract}
Para atender à sua finalidade geral, a CNEA formulou os seguintes objetivos: (a) realizar estudos e levantamento sobre os problemas sociais, econômicos e culturais das áreas a serem objeto da experiência; (b) ampliar o sistema escolar primário das áreas assistidas pela campanha, de forma a tender toda a população de sete a 11 anos, num curso de cinco anos de estudos; (c) criar novas classes, em caráter de emergência, para a população de mais de 11 anos e menos de 15 anos de idade; (d) organizar um sistema de educação de base para a população rural, de forma a melhorar a produção agrícola; e (e) instalar classes de alfabetização educação e adultos (maiores de 15 anos) nos locais cujas condições socioeconômicas da população favorecessem a uso funcional da leitura e da escrita. Além desses objetivos, recomendações quanto à organização de classes, aperfeiçoamento do magistério, reformulação de currículos, dinamização de escolas rurais e organização de cooperativas de produção também foram formuladas pela campanha.
\end{abstract}

Apesar desses amplos objetivos e reforma dessa nova campanha, essa ainda não foi o bastante para acabar de vez com o analfabetismo brasileiro, a vergonha nacional perante outros países. Na tentativa de subir nos conceitos internacionais, e melhorar a posição social da população outras novas campanhas surgiram, movimentos particulares e em regiões isoladas, cada um com uma caraterística a mais.

Em 1963, as três Campanhas anteriores de alfabetização de adultos (CEAA, CNER, CNEA) foram extintas por não atender a nova maneira de compreender o fenômeno do analfabetismo, bem como os interesses políticos da época. Desde então, a questão da educação de adultos teve uma nova roupagem, passou a ser percebida de um ponto vista politico e ideológico que envolvia essencialmente à participação popular.

Depois do mandato de Kubistchek, a país elegeu um novo presidente, Jânio Quadros, tomando posse em janeiro de 1961. Dentre suas ações política como presidente, no tocante a educação ele apoio o Movimento de Educação de Base (MEB), o qual nasceu da igreja católica, onde na conferência Nacional dos Bispos do Brasil, a igreja propôs ao Presidente a realização 
Id on Line Revista Multidisciplinar e de Psicologia

Id on Line Multidisciplinary and Psycology Journal

de um projeto de Educação de Base, para atender, preferencialmente, o meio rural nas Regiões menos assistidas nas campanhas anteriores ou que menos desenvolveram suas metas.

A renúncia de Jânio em 1961 deixou o país em choque, temeroso pelo vice que veio a assumir a presidência, João Goulart. O novo presidente passou a tratar a questão da educação de adultos sob outra ideologia política, na qual a participação social e comunitária era prioritária.

A UNE, União Nacional dos Estudantes criou em 1963 o centro de cultura popular (CCP), no qual os membros estudantes de vários lugares e culturas desenvolviam diversas atividades ao ar livre, nas praças e de frente às fábricas, bem como: peças de teatro, atividade educativas, culturais e musicais, das quais foram bem aceitas pelas ouvintes.

As condições socioeconômicas da época eram precárias. Os professores de jovens e adultos não eram formados para o magistério, possuíam apenas algumas horas de treinamento realizadas em espaço improvisado, igreja, empresas ou ambientes particulares. A aula era apenas 2 horas diária, no turno noturno e praticamente sem muitos recursos. O alfabetizador que dava sorte tinha a sua disposição um mimeografo para fazer suas tarefas, outros, porém, só dispunha da lousa e do giz branco.

Após a Segunda Guerra Mundial, o mundo estava dividido em dois lados: União Soviética e os Estados Unidos. O Brasil por razões políticas e econômicas escolheu ficar do lado do segundo. Nos anos 50 surgiram também os termos de país desenvolvido e país subdesenvolvido, no qual o Brasil está incluso. E por esta razão, Juscelino Kubitscheck como governo da nação, planejou fazer algo marcante no país, o que de fato fez, construiu o Distrito Federal, adquiriu dívidas externas, proporcionou um grande avanço industrial e tecnológico à nação. Esses anos são verdadeiros de muitas mudanças, de momentos inesquecíveis e histórico, tanto no social como no econômico e político, considerados os "Anos Dourados"

Os esforços empreendidos durante as décadas de 1940 e 1950 fizeram cair os índices de analfabetismo das pessoas acima de cinco anos de idade para 46,7\% no ano de 1960 . Os níveis de escolarização da população brasileira permaneciam, no entanto, em patamares reduzidos quando comparadas à média dos países do primeiro mundo e mesmo de vários dos vizinhos latino-americanos. (HADDAD, PIERRO, 2000, p.111)

Está claro que mesmo com as diversas campanhas realizadas, os vários momentos, parceria e políticas de educação de massa não tinha sido o suficiente para banir de uma vez o analfabetismo brasileiro. O país ainda contava com 46,7\% de analfabetismo acima de 5 anos de idade. 
Id on Line Revista Multidisciplinar e de Psicologia

Id on Line Multidisciplinary and Psycology Journal

\section{O Mobral}

Nos primeiros anos de regime militar, não houve iniciativa federal para retomar o trabalho de alfabetização de adultos. Apenas um programa, a CRUZADA ABC (Cruzada de Ação Básica Cristã), de caráter semioficial, funcionou em boa parte do país, dirigida por evangélicos norte-americanos (CARVALHO, 2010 apud HADDAD; PIERRO, 2000, p. 114).

O Movimento Brasileiro de Alfabetização surgiu no período posteriormente a CRUZADA ABC ainda do regime militar, pelo decreto $\mathrm{n}^{\circ}$ 62.455, de 22 de março de 1968, conforme autorizado pela lei $\mathrm{n}^{\mathrm{o}} 5.379$, de 15 de dezembro de 1967. Com o objetivo de minimizar as tensões existentes no país e aplacar de vez com a vergonha nacional, o analfabetismo, o governo brasileiro lançou em 1968 o MOBRAL, mais uma tentativa de elevar os índices de alfabetização da população nacional.

O MOBRAL estava ligado diretamente as ideias, métodos e filosofia do educador Paulo Freire, educador brasileiro que tinha uma técnica educativa diferenciada e muita aceita na esteira educacional. O seu método gira em torno da palavra-geradora para alfabetizar, enquanto o Mobral utilizava palavras do cotidiano dos alunos jovens e adultos.

O objetivo maior desse curso de duração de 9 meses era tão somente promover a alfabetização funcional e educação continuada para analfabetos acima de 15 anos ou mais. Esse projeto teve um efeito gigantesco, atingiu todo o país, cidades e municípios, entretanto depois de dez anos avaliou-se que o resultado não foi o suficiente para mudar a realidade do país. A insatisfação se deu pela falta de continuidade dos estudos para os alunos que entravam e saiam do curso logo que ele acabava e não continuavam a estudar. Não era o bastava aprender a escrever o seu nome e ler e escrever palavras do dia a dia, isso não se faz suficiente para sair da condição de analfabeto funcional.

Nos anos 80 com a recessão econômica sofrida pelo país, impossibilitou a continuidade do programa MOBRAL, o qual passou a ser chamado de Fundação Nacional para Educação de Jovens e Adultos - EDUCAR em 1985. Cinco anos depois, em 1990 a Fundação EDUCAR também foi extinta mesmo com o país cheio de analfabetos. 
Id on Line Revista Multidisciplinar e de Psicologia

Id on Line Multidisciplinary and Psycology Journal

\title{
A Proposta Pedagógica de Paulo Freire
}

Freire abominava a educação bancária, considerada por ele como uma educação pobre e limitada, a qual colocava o aluno como um “Zé ninguém”, aquele que não sabia de nada e não devia aprender, ou seja, o professor era o único que tinha conhecimentos digno de crédito. $\mathrm{O}$ aluno da referida educação era como um saco vazio, uma espécie de banco no qual o mestre deveria depositar o conhecimento. Para rebater esse pensamento, o educador pernambucano Paulo Freire fez menção da educação transformadora, onde o aluno é importante no processo, seus saberes e ações devem ser aproveitados e valorizados. Ainda com o mesmo autor, em (1979), ele diz:

\begin{abstract}
A educação é uma resposta da finitude da infinitude. A educação é possível para o homem, porque este é inacabado e abe-se inacabado. Isto leva-o à sua perfeição. A educação, portanto, implica um busca realizada por um sujeito que é o homem. $\mathrm{O}$ homem deve ser o sujeito de sua própria educação. Não pode ser o objeto dela. Por isso ninguém educação (p.8).
\end{abstract}

O homem como sujeito de sua própria educação é o sujeito que pensa, questiona e dar sugestões, provoca algumas reações. Por essa razão o professor é considerado um mediador entre o ensino e o aluno, ele deve mediar através de diferentes métodos, instigar o que lhe foi ensinado. A consciência bancária realmente não é futuro promissor para nenhum ser humano, porque o que é arquivado, depositado é o próprio indivíduo e isso lhe rouba o direito, a capacidade de criar, de fazer e de pensar. Nessa direção, Freire (p.15) reafirma "o destino do homem deve ser criar e transformar o mundo, sendo o sujeito de sua ação." Belíssima expressão, a dizer que o homem é o sujeito de suas ações, isso nos leva a compreender que este é capaz de tudo, de ir e vi, realizar voos altos, dependendo sobretudo de seu estado inicial de querer buscar.

O educador citado acreditava que a educação libertasse os homens e mulheres oprimidos pelo sistema, pela falta de assistência social e conseguintemente da pobreza e inferioridade, na qual estavam vivendo. Essa classe oprimida e marginalizada era desprezada, excluída dos momentos decisivos no país, sem sequer o direito ao voto. Direito esse que só foi conquistado muitos anos depois, na Constituição de 1988. Para Freire a educação além de libertar, dava consciência de seus direitos e deveres sociais e civis. "A educação é um ato 
Id on Line Revista Multidisciplinar e de Psicologia

Id on Line Multidisciplinary and Psycology Journal

político, que pode contribuir para a transformação social e a libertação dos oprimidos" (Freire, 1981, p.29-61).

\section{O método de Laubach}

Laubach esteve no Brasil realizando palestra e cursos para explicar como funcionava o seu método de ensino, tão bem aceito em vários países do mundo. $\mathrm{O}$ método de ensino de Laubach tinha o aluno como o centro do processo, seus acertos e erros eram considerados importantes para avaliação do conhecimento. Quando um aluno errava, a correção era feita de maneira amigável, procurando mantê-lo motivado nos estudos.

Todos os alunos deveriam ser considerados iguais em direitos e deveres, cabendo ao alfabetizador a tarefa de ajuda-los a construir seus conhecimentos, afinal de contas eles são capazes. As palavras de ânimo e conscientização deveriam fazer parte do vocabulário do educador, bem como uma relação harmoniosa e saudável com o estudante jovem e adulto.

O assunto abordado nas aulas deveria ser de conhecimento de todos, ou seja, do cotidiano da turma e o docente tinha a responsabilidade de propor umas atividades de leitura e escrita sem grandes dificuldades ou abstrações, no intuito que o alfabetizando sentisse capaz de ler palavras e se possível até um pequeno texto na primeira aula (SOEK, et al, p.9-10,2009)

Cabia ainda ao professor orientar o processo de construção e compreensão da linguagem oral e escrita, utilizando objetos concretos. Mediante a alegação que não importa a idade para prender, todos são considerados capazes de tal fascínio, pois aprender a ler e escrever são atividades possíveis aqueles que não são mais tão jovens.

O docente, além de todas suas atribuições não podia esquecer-se do respeito às diferenças individuais dos alunos, bem como o ritmo próprio de aprendizagem. Os materiais e recursos utilizados deveriam ser adaptados pelo educador para atender as suas necessidades. Se a escola não disponha de muitos recursos, o docente deveria está apto para usar de sua criatividade, aproveitando o máximo que tinha. Enfim, deveria cumprir seu papel de mediador em todos os momentos e circunstancias.

Para o educador Laubach (s.d.) o adulto que não tinha estudo não deixava de ser uma pessoa importante, com conhecimentos e instruções valiosas, mesmo que não soubesse ler e 
Id on Line Revista Multidisciplinar e de Psicologia

Id on Line Multidisciplinary and Psycology Journal

escrever. $\mathrm{O}$ conhecimento informal era de grande valia, o adulto apenas não teve oportunidade de acesso ao conhecimento formal. Foi nessa primeira campanha de jovens e adultos que criaram pela primeira vez um material didático especifico para essa modalidade de ensino.

\section{Considerações Finais}

A Educação de Jovens e Adultos sempre foi um problema para o país, desde a época da colonização pelos portugueses.

Pesquisa do IBGE, 2010 revela que a taxa de analfabetismo geral vem diminuindo no Brasil pelo $6^{\circ}$ ano consecutivo. Isso é louvável, significa que apesar de muitas falhas das politicas públicas para educação, algo tem sido efeito. As campanhas de Educação em massa não foram em vão, apesar dos poucos resultados tiveram sua parcela de colaboração no que o país é hoje, elas valeram a pena, porque a semente foi plantada, governo após governo lançaram suas campanhas e projetos, muitos foram alfabetizados, embora numa escala bem pequena.

Dentre de uma década, o mínimo total de matrícula na educação de Jovens e AdultosEJA, no Brasil não passou de 5,7 milhões e, desde 2006, esse número vem caindo anualmente, embora outros dados revelassem que o número de brasileiro acima de 25 anos que não tem instrução ou não completaram o ensino fundamental cresceu de 51,2 milhões para 54,4 milhões entre 2000 e 2010. (IBGE, 2010)

A realidade é que essas pessoas adultas que não terminaram o ensino médio trabalha o dia todo e pelo cansaço não se sentem dispostos a saírem a noite para estudar. Muitos, até desejam, têm a consciência que precisam, mas suas condições econômicas são difíceis, o que impede de buscar melhorias para sua vida.

Quando um adulto decide voltar à escola, é uma grande conquista da sociedade, este sim, fará de tudo que estiver ao seu alcance para concluir o curso iniciado. Por outro lado, quando é um jovem, as coisas são bem diferentes, a maioria sai de casa, mas não chegam à escola, desviam-se de livre e espontânea vontade de caminho. As que chegam à escola, não permanecem por muito tempo, costumam "matar" aulas para se divertirem, seja para namorar ou para beber e jogar. Essa é uma realidade, principalmente nas comunidades do interior. 
Id on Line Revista Multidisciplinar e de Psicologia

Id on Line Multidisciplinary and Psycology Journal

Outras questões a ser observada é a formação do professor da EJA. Infelizmente não há critérios específicos para essa seleção, geralmente um docente com uma formação inicial em qualquer área pode ser o professor dessa modalidade de ensino, e isso, é com certeza, algo comprometedor, prejudica muito o ensino aprendizagem.

$\mathrm{Na}$ prática as prefeituras fazem contratações de pessoas que nunca foi professor, ou seja, é um ser que não tem nenhuma noção do que é uma sala de aula, especialmente de adultos já formados, cheios de conhecimentos e concepções de mundo diferenciadas. Esses novos contratos estão preocupados com seu baixo pagamento de voluntariado, com o horário que terminará a aula e não em criar uma boa relação entre professor e aluno, aluno e aluno, para que de fato aconteça uma educação de qualidade e que proporcionem melhores condições de vida para os discentes.

Para Paulo Freire (1999), a formação de professor para atuar na EJA é preciso suprir algumas características específicas, bem como: enfatizar o compromisso do docente com seu fazer e com seu aluno, um compromisso ético, permeado de diálogo e harmonia. As ideias de democracia, conscientização, transformação, diálogo e respeito ao aluno como ser agente pensante e capaz de ter opiniões e ser útil a sociedade que está inserida. Enfim, o professor para atuar na EJA não pode ser um professor comum, é preciso ser bem preparado, que se esforce bastante aponto de conhecer a realidade da sua clientela estudantil, suas preferências e medos, além do interesse educacional.

Não basta ensinar a ler e escrever somente os códigos da linguagem, o docente da EJA, deve como mediador do conhecimento contextualizar as letras e os números dentro da vida real dos seus alunos adultos, só assim, eles poderão sim, permanecer no curso, tendo em vista que estão aprendendo de forma significativa para si e para o trabalho e para a convivência social com seus semelhantes.

\section{Referências}

BRASIL, CEAA. O Analfabeto em face do direito. Rio de Janeiro: Ministério da Educação e Saúde, Departamento Nacional de Educação, 1948 .

BOULOS JÚNIOR, A. HISTÓRIA: Sociedade \& Cidadania. $1^{a}$ edição. São Paulo: FTD, 2006. Coleção História : Sociedade e Cidadania. 
CARVALHO, M. Primeiras Letras: Alfabetização de Jovens e adultos em espaços populares. Ed. EDITOR ÁTICA, $1^{\text {a }}$ Edição. São Paulo. 2010.

FREIRE, P. Educação e Mudança. 12a ed. Editora PAZ e TERRA. ANO, 1979.

Pedagogia do Oprimido. 10. Ed. Rio de Janeiro: PAZ E TERRA, 1981.

GALVÃO, A. M. de O; SOARES, L. J. G.; História da alfabetização de adultos no Brasil. In: ALBUQUERQUE, E.D,; LEAL, T.F.A Alfabetização de Jovens e Adultos: em um perspectiva de letramento. Belo Horizonte: Autêntica, 2004.

HADDAD, S.; DI PIERRO, M.C. "Escolarização de jovens e adultos". Revista Brasileira de Educação. Associação Nacional de Pós-Graduação e Pesquisa em Educação, Rio de Janeiro, n. 14, maio/ago.2000, p. 108-194.

LAUBACH, Frank C. Os Milhões silenciosos falam. S.1., s.e., s.d.

SOEK, A. M. HARACEMIV, S.M.C. STOLTZ, T. Mediação Pedagógica na Alfabetização de Jovens e Adultos. Ed. Positivo, $1^{\text {a }}$ edição, 2009.

Como citar este artigo (Formato ABNT):

LOPES, E.S.; SILVANA, F.S.; DAMASCENO, E.G. campanhas de Educação de Jovens e Adultos - EJA. Id on Line Revista Multidisciplinar e de Psicologia, Nov-Dez. de 2016, vol.10, n.32, p. 147-163. ISSN: 1981-1179.

Recebido: $29 / 08 / 2016$

Aceito: $17 / 09 / 2016$ 